\title{
Nuevas formas del movimiento obrero: las empresas recuperadas por sus trabajadores en Argentina. Articulaciones políticas y estrategias de inserción económica
}

\author{
Alejandro PIZZI \\ Departamento de Gestión de Empresas, Área Sociología \\ Universidad Rovira i Virgili, \\ alejandro.pizzi@urv.cat \\ Ignasi BRUNET \\ Departamento de Gestión de Empresas, Área Sociología \\ Universidad Rovira i Virgili, \\ ignasi.brunet@urv.cat
}

Recibido: 17-09-2010

Aceptado: 13-07-2011

\section{RESUMEN}

El artículo tiene por objetivo analizar la evolución organizacional del movimiento de recuperación de empresas en Argentina (2001-2009) y su vinculación con las estrategias de articulación productiva entre ellas, constituyendo de este modo los primeros intentos de conformar nuevos espacios de economía social. Para ello desarrollamos, en primer lugar, una tipología de incentivos a la acción colectiva. En segundo lugar, analizamos la conformación y dinámica de organizaciones políticas dentro del movimiento social. En tercer lugar, describimos las primeras estrategias de articulación económica entre empresas recuperadas, que tienen en aquellas organizaciones políticas una de sus condiciones de posibilidad. Nuestra hipótesis es que en la medida en que el movimiento social sea política y organizativamente débil prevalecerán estrategias de inserción individual al mercado por parte de las empresas, mientras que una mayor integración y profundización de lazos de confianza política entre las mismas favorece las condiciones para proyectar estrategias de integración productiva.

Palabras clave: empresas recuperadas, autogestión, movilización social, cooperativas

\section{New forms of the labour movement: the companies recovered by his workers in Argentina. Political articulations and strategies of economic insertion}

\begin{abstract}
This article's objective is the analysis of the organizational evolution of the movement of Recovered Companies in Argentina and its relation to the strategies of productive articulation among them, representing hereby one of the first attempts for the creation of new spaces within social economy. Hence we've developed, in the first place, a typology of incentives to collective action. Secondly, we analyze the formation and the dynamics of political organization within the social movement. Thirdly, we describe the first strategies of economic articulation between recovered companies, which find in these political organizations one of the
\end{abstract}


conditions that makes the economic articulation possible. It is precisely our hypothesis that, as the movement is politically and organizationally weak, strategies of individual insertion to the market by companies will prevail, and on the other hand, the greater is the integration and the trust bond between them encourages the conditions to project productive integration strategies.

Keywords: recovery companies, self-management, social mobilization, co-operatives

REFERENCIA NORMALIZADA

Pizzi, A. y Brunet, I., (2012) Nuevas formas del movimiento obrero: las empresas recuperadas por sus trabajadores en Argentina. Articulaciones políticas y estrategias de inserción económica. Cuadernos de Relaciones Laborales Vol. 30, núm. 2, p. 563-583.

SUMARIO: Introducción. 1. La teoría de la acción colectiva y las alternativas del movimiento obrero. 2. El contexto social de la recuperación de empresas. 3. Incentivos de la movilización. 4. Estructuras de movilización y articulación económica. 5. Conclusión. 6 . Referencias bibliográficas.

\section{Introduccion}

Desde la crisis socioeconómica argentina de 2001 y 2002 se extiende por el país un fenómeno de recuperación, por parte de los trabajadores, de empresas en quiebra, como medio para salvar las fuentes de trabajo. Tales empresas de trabajadores conforman un movimiento social, con raíces en el movimiento obrero argentino, y se mantienen en el mercado por medio de estrategias colectivas de autogestión, mayoritariamente bajo la figura legal de cooperativas de trabajo. Sobre la base de una investigación de mayor aliento, en este artículo se elabora una tipología de incentivos sociales a la acción colectiva y su relación con la creación de organizaciones y condiciones políticas sobre las que se sostienen las primeras estrategias de construcción de espacios de economía social entre los trabajadores de este movimiento. Específicamente, nos preguntamos ¿cómo influye el tipo de construcción sociopolítica del movimiento social sobre las formas de inserción económica de las empresas recuperadas? Esto es, ¿de qué manera se van conformando nuevos espacios de economía social por parte de estos trabajadores? Como hipótesis planteamos que existe una relación positiva entre el grado de fortaleza política del movimiento social, que implica un mayor nivel de movilización, por una lado, y las posibilidades de articulación de un espacio económico entre empresas recuperadas, por otro lado. Concretamente, en tanto el movimiento sea social y políticamente débil, en cada unidad productiva recuperada tenderá a prevalecer una estrategia económica adaptativa individual de inserción en el mercado. Por el contrario, a medida que se fortalezca la movilización habrá más oportunidades de progresar en la integración económica entre empresas recuperada en un espacio de economía social. En este sentido, el principal aporte del artículo consiste en presentar un análisis actualizado de la dinámica política de este movimiento, sobre la base del esclarecimiento de los distintos tipos de incentivos a la participación, y el impacto que dicha dinámica ha tenido sobre las estrategias económicas colectivas de las empresas recuperadas. En otras palabras: la determinación de las condiciones sociopolíticas de construcción de nuevos espacios de economía social. 
La investigación que llevamos a cabo fue de naturaleza cualitativa; para ello se elaboró una muestra estructural que abarcó a la mayoría de los sectores económicos que cubren las empresas recuperadas, dando cuenta de diferentes realidades de mercado: metalúrgicas, gráficas, editoriales, hotelería, industrias plásticas, textiles, calzados, trasporte, cristalerías y frigoríficos. También se respetó el criterio del tamaño de la empresa al incluir organizaciones con menos de diez socios; Pymes de hasta 50 trabajadores; empresas medianas de entre 51 y 100 trabajadores, y empresas grandes de más de 100 trabajadores. Además, incluimos, de forma pareja, empresas de la Ciudad Autónoma de Buenos Aires y de la Provincia de Buenos Aires. Asimismo, se incluyó a experiencias que surgieron en las primeras etapas del movimiento, así como otras que ocurrieron posteriormente, incorporando también casos muy recientes. De igual forma, se tuvo en cuenta el criterio de entrevistar a trabajadores que responden a distintos espacios políticos dentro del movimiento general, y dentro de estos conjuntos, a conducciones más y menos comprometidas con la política del movimiento. También se tuvo en cuenta casos que debieron atravesar por un duro conflicto, que incluyó tomas de la planta, la negativa de los dueños a perder la empresa, intentos de desalojo, etc., hasta casos en los que desde el inicio se desarrolló una salida consensuada entre las partes. Entre ambas situaciones, se entrevistaron muchos casos ubicados en puntos intermedios, que incluyeron algunas medidas de fuerza y soluciones negociadas. Por tanto, no aspiramos a obtener una representatividad extensiva, sino la búsqueda de sujetos que reproduzcan, en una escala experimental, relaciones estructurales junto con los discursos que se adscriben a esas posiciones sociales y de esta manera proyectar algún tipo de información a un conjunto mayor, sobre el supuesto de homogeneidad interna de una "posición estructural". Para ello llevamos a cabo veintidós entrevistas en profundidad (realizadas entre noviembre de 2008 y enero de 2009), complementadas con estrategias de observación directa, a través de visitas a empresas y a reuniones de los movimientos sociales. Con relación a la técnica de análisis de la información obtenida, nos basamos en el análisis de discurso, considerando las estructuras discursivas como mediadoras de la acción social, lo que permite comprender la evolución, conflictos y diversos escenarios del objeto de estudio.

El artículo está organizado en cuatro secciones. En la primera, desarrollamos las líneas básicas de las teorías de la acción colectiva, porque nos permite elaborar un modelo de interpretación de las estrategias de las empresas recuperadas al movilizar sus recursos para conformar espacios incipientes de economía social. En la segunda, describimos el contexto social argentino que proveyó los incentivos iniciales a la acción colectiva de recuperación de empresas. En la tercera sección profundizamos el análisis desarrollando los principales tipos de incentivos a participar en el movimiento social. En la cuarta, delineamos la evolución de las estructuras de movilización creadas, y el impacto que tienen sobre las incipientes estrategias de articulación económica entre empresas recuperadas, base de la construcción de nuevos espacios de economía social. Por último, a modo de conclusión, exponemos las consideraciones finales de los resultados de la investigación. 


\section{La teoría de la acción colectiva y las alternativas del movimiento obrero}

Dentro de la sociología de los movimientos sociales existen dos grandes corrientes que abordan su objeto de estudio desde diferentes presupuestos teóricos y epistemológicos (Laraña y Gusfield, 1994; Casquette, 1998; Laraña, 1999; Robles, 2002). Por un lado, las teorías de los Nuevos Movimientos Sociales, de raigambre europea, interpretan a éstos como expresiones de cambios estructurales en la sociedad contemporánea y como experiencias de acción colectiva diferentes de los movimientos clásicos de los trabajadores organizados, ya que el declive del conflicto central de la sociedad industrial relega al movimiento obrero a un segundo plano. Dentro de este paradigma, a su vez, se inscriben diversos autores (Touraine, 1990; Melucci, 1994, entre otros) que enfatizan distintas dimensiones de las transformaciones de la estructura social y los movimientos originados de ella. Por otro lado, la teoría de la Movilización de Recursos, de origen norteamericano, se vale de un planteamiento más instrumental, ya que su principal preocupación es estudiar la eficacia con que las distintas organizaciones (que juntas conforman un movimiento social) hacen uso de los recursos disponibles para la consecución de objetivos, aprovechando las oportunidades políticas que se les presentan, e interpretando discursivamente dichas oportunidades como tales. Aquí reseñamos sintéticamente sus distintos enfoques y marcamos algunas limitaciones que, a nuestro criterio, adolece y, en función de ello, proponemos una articulación teórica con otras perspectivas que aplicamos luego en nuestro análisis empírico.

La Teoría de la Movilización de Recursos ha puesto su énfasis en la capacidad de obtener y gestionar un conjunto diverso de recursos por parte de los movimientos con el fin de comprender las características de su estructura organizativa, su potencial de movilización y de incidencia en la acción colectiva (McAdam et al. 1999). En este marco, la movilización se define como el proceso por el cual un grupo adquiere el control colectivo sobre los diferentes tipos de recursos que necesita para su acción, más que el simple aumento de los mismos (Tilly, 1978) y las estructuras de movilización constituyen aquellos canales colectivos, tanto formales como informales, a través de los cuales los individuos pueden movilizarse e implicarse en los movimientos sociales, centrando su interés en el análisis comparado de las infraestructuras organizativas de los actores "con el objetivo de comprender mejor los patrones históricos de movilización y predecir cuáles facilitan la emergencia, eficacia y consolidación de los movimientos" (Ibarra et al. 2002: 40). Por tanto, su principal preocupación es estudiar la eficacia con que las distintas organizaciones (que juntas conforman un movimiento social) hacen uso de los recursos disponibles para la consecución de objetivos (Snow et al. 1980; McCarthy, 1996; Kriesi, 1996). En este sentido no es posible hablar de un movimiento social dado como una entidad homogénea, sin considerar las distintas orientaciones ideológicas, organizativas $\mathrm{y} / \mathrm{o}$ estratégicas que conviven en su seno.

Dentro de este paradigma, la Teoría de las Oportunidades Políticas constituye la perspectiva que apela sistemáticamente a la naturaleza social de los incentivos para actuar colectivamente en un movimiento social. Para Tarrow (1997: 58) los indivi- 
duos se suman a los movimientos sociales como respuesta a las oportunidades políticas, y en su dinámica posterior crean nuevas oportunidades a través de la acción colectiva: "Los movimientos surgen cuando se amplían las oportunidades políticas, cuando se demuestra la existencia de aliados y cuando se pone de relieve la vulnerabilidad de los oponentes". Estas oportunidades, que son evaluadas por los protagonistas y constituyen los incentivos (sociales) para actuar colectivamente, implican coyunturas que reducen los costos de la movilización, en la medida en que los actores descubren aperturas institucionales, elites vulnerables o sinergias con otros procesos sociales (McAdam, 1988). Para analizar las oportunidades políticas se consideran variables estructurales del sistema político, relacionadas con factores de cierta estabilidad: 1) el grado de apertura en el acceso a la participación política; 2) los cambios o realineamientos de los gobiernos; 3) la disponibilidad de aliados influyentes o de vínculos entre los individuos movilizados y ciertos miembros del cuerpo político o estatal; 4) las divisiones entre las elites dirigentes, o en el seno de las mismas, que pueden generar contextos oportunos que incentiven la acción colectiva, y 5) la capacidad estatal para reprimir los movimientos sociales y su tendencia a hacerlo. La relación entre oportunidades políticas y movilización se estudian desde dos perspectivas. Por un lado, para la visión macro-sociológica racionalista los movimientos se analizan como respuestas a la expansión de oportunidades políticas, otorgando a las organizaciones formales la oportunidad de emprender una movilización de manera exitosa. Por otro lado, la visión microsociológica interpreta que los individuos son estimulados a participar en movimientos sociales porque están inmersos en unas redes de asociaciones que les confieren disponibilidad estructural para la protesta y la movilización (McAdam, 1994).

Un factor vinculado a las oportunidades políticas, y que constituye un recurso que facilita la movilización, son los repertorios de la acción colectiva (Tilly, 1978, 2002). El mismo refiere a los modos recurrentes de acción que llevan a cabo los movimientos sociales y remite a la transferibilidad de formas de movilización reconocidas a través del tiempo y del espacio, ya que constituyen productos culturales aprendidos que surgen y cobran forma a partir de confrontaciones anteriores, y se van transformando en función de las fluctuaciones en los intereses, las oportunidades y la organización de los movimientos sociales. Otro concepto que vincula las oportunidades políticas con la movilización es el "ciclo de protestas", observable cuando, bajo una determinada constelación de circunstancias, el conflicto protagonizado por uno o varios movimientos sociales se generaliza en el sistema social hasta constituir un ciclo de protesta, que configura una fase de intensificación del conflicto y del enfrentamiento a lo largo del sistema social (Tarrow, 1997, 2002).

Además, la movilización tiene una dimensión cultural insoslayable, porque los individuos no pueden emplear rutinas de acción colectiva que desconocen. Cada sociedad tiene una reserva de formas familiares de acción conocidas tanto para los activistas y promotores como por sus oponentes, y que son productos/convenciones culturales. Para Teoría del Proceso Colectivo de Interpretación las oportunidades políticas y la movilización social son el resultado de un proceso de rupturas culturales que hacen aflorar a la superficie contradicciones latentes (Zald, 1999), y que 
reformulan o cuestionan las definiciones estándar de la situación social que es objeto de críticas por parte de los movimientos. Desde esta perspectiva, una tarea fundamental de éstos consiste en: 1) señalar agravios e injusticias; 2) vincularlos a otros agravios para visualizar una trama política más compleja de injusticias; 3) argumentar posibles soluciones a los problemas planteados, y 4) construir marcos de significados más amplios que puedan encontrar eco en la predisposición cultural de una población (Ibarra et al. 2002). No obstante, la creación de marcos interpretativos constituye un proceso de lucha y negociación interna entre distintos agentes que defienden puntos de vista divergentes dentro de un movimiento social. Estos marcos en disputa dentro del movimiento se fundamentan en las luchas por imponer un sentido sobre las oportunidades políticas, las organizaciones y las estrategias a seguir.

La teoría de la Movilización de Recursos no tiene un desarrollo sistemático sobre la disponibilidad estructuralmente diferenciada de los recursos entre distintos sectores de la población que corresponden a diferentes clases sociales. Sin embargo, consideramos que, especialmente en su versión de las oportunidades políticas, puede integrarse en una visión dinámica de relaciones entre clases sociales, de los mecanismos de explotación y dominación (Mouriaux y Beroud, 2000), al incorporar la dimensión clasista del conflicto como variable estructural. La misma determinaría que las distintas clases sociales tienen a su disposición diferentes medios y recursos de acción (Wright, 1994), dada la estructura de desigualdad material de la sociedad, para obtener mejoras en su bienestar social y económico.

Dicho esto, y considerando que analizamos la movilización de una fracción de la clase obrera argentina, debemos completar el marco conceptual del abordaje empírico de nuestro objeto planteando brevemente la relación teórica y práctica entre los movimientos sociales y el movimiento obrero en particular. Algunos académicos de las relaciones laborales han puesto de relieve que los sindicatos siempre han estado en crisis (Hyman, 1994). Específicamente, la crisis de representación sindical, vinculada al desmoronamiento del régimen fordista de acumulación y a la emergencia del neoliberalismo y la consolidación de la precariedad laboral, se refleja tanto en la problemática del "representation gap" sindical (Charlwood, 2002; Jodar et al. 2005) como en el reto de la renovación sindical. Esto es así en tanto que del sindicalismo de clase apenas queda nada, como indica Lacalle (2006), y constituye una especie no protegida en vías de extinción. Con una clase obrera sustancialmente transformada, objetivamente desproletarizada (Hobsbawm, 1989), y profundamente segmentada, y con una conciencia de clase en claro declive. De hecho, los marcos de interpretación del sindicalismo tradicional están orientados hacia el sector de trabajadores formales. Para superar esta tradición la renovación política y sindical debería abarcar diferentes y novedosas articulaciones, máxime teniendo en cuenta que las formas de vida $\mathrm{y}$, junto con ellas, la conciencia de la situación social y laboral de la mayoría de los asalariados ha cambiado. Incluso más drásticamente que su composición interna.

La revitalización sindical implica construir una organización y un proyecto con un horizonte superior al propio sindicato, articulando el lugar de trabajo, la comuni- 
dad y los sectores populares desposeídos; promover la movilización; ampliar la base social; y establecer relaciones fluidas entre diferentes niveles sindicales (Senén González y Haidar, 2009). La "revitalización" o "renovación" sindical se refiere tanto a la movilización como a un conjunto de estrategias de recuperación de la fortaleza de las organizaciones sindicales en distintos contextos nacionales. Ello demanda organizar nuevos miembros, reestructurar la organización, construir coaliciones con otros movimientos sociales, asociarse con empleadores, actuar políticamente, establecer vínculos internacionales, etc. (Frege y Nelly, 2003). De esta forma, a partir de la construcción de coaliciones el sindicalismo comienza a ser parte de la lucha por la justicia social, lo laboral se vincula con los movimientos de derechos humanos, medioambientales, religiosos, estudiantiles, feministas, etc., y estas movilizaciones van atrayendo a nuevos miembros (Senén González y Haidar, 2009).

Desde esta perspectiva, se considera un reduccionismo limitar el movimiento obrero a su organización sindical porque excluye otras formas de revitalización, y muchas experiencias que van por fuera del sistema de negociaciones colectivas quedan invisibilizadas como prácticas de renovación del movimiento obrero. En este marco, el concepto de sindicalismo movimientista o sindicalismo de movimiento social nombra a aquellas experiencias surgidas desde las propias organizaciones sindicales que transforman, amplían sus objetivos y sus bases de representación con el objetivo de convertirse en un actor sociopolítico novedoso (Moody, 1997; Lambert, 2002; Waterman, 2005; Clawson, 2003; Webster et al. 2008).

Sin embargo, otra posición plantea que el movimiento obrero sindical es más un agente del mercado de trabajo que un movimiento social (Sullivan, 2010). Los sindicatos son actores económicos restringidos al ámbito laboral y a un sistema de relaciones industriales basado en una economía de mercado. En esta línea, el fortalecimiento sindical está en función de su densidad de afiliación (Bronfernbrenner y Juravich, 1998; Heery et al. 2003). Hyman (2001) también distingue entre la organización sindical y los movimientos sociales, aunque señala que los sindicatos emergieron universalmente como movimientos sociales. Para este autor, los sindicatos se encuentran entre una organización de servicios profesionalizada, por una lado, y una expresión y vehículo del movimiento histórico de las masas trabajadoras sumergidas. En esta línea, la consideración del movimiento sindical como movimiento social per se deja de lado los rasgos específicos del sindicalismo y las relaciones particulares en las que los sindicatos están insertos. No obstante, para que una estrategia de fortalecimiento sindical basada en el critero de la densidad funcione adecuadamente (los sindicatos como agentes del mercado laboral y no como movimientos sociales) se requiere un sistema viable de relaciones laborales afianzado, que otorgue relevancia política y económica a la clase obrera, que es el que pone en entredicho el capitalismo flexible neoliberal. Por tanto, en las condiciones dadas por la hegemonía de un capitalismo neoliberal y flexible, la renovación y empoderamiento sindical depende del desarrollo de un saber práctico contrahegemónico capaz de organizar y movilizar a los trabajadores (Biyanwila, 2008). En definitiva, para comprender lo que 
generan/construyen los movimientos sociales, y en particular la renovación del movimiento obrero, debemos centrarnos en el nivel de la práctica social, aquello que Hyman (1971) llamó "lucha de prácticas" (praxis of struggle).

\section{El contexto social de la recuperación de empresas}

La crisis económica y social de Argentina en 2001 y 2002 fomentó los incentivos sociales en una franja de los trabajadores para que recuperaran sus empresas en crisis y las autogestionasen, como estrategia para enfrentar la amenaza de la desafiliación social (Castel, 2000). El cuadro social correspondiente arrojaba a 13 millones de personas bajo la línea de pobreza en 2001, y 19 millones en 2002, y 4 millones de personas se hallaban bajo la línea de indigencia en 2001, y 9 millones en 2002. La caída salarial, la regresiva distribución de los ingresos, la precarización de las condiciones laborales y el desempleo (Salvia, 2004, Rapoport, 2005), se constituyeron en los factores estructurales que explicaban la intensidad de la pobreza, el incremento de su heterogeneidad (que comienza a abarcar a estratos medios) y la agudización de su intensidad entre los más carenciados (Beccaria, 2007, 2001).

En este contexto, el fenómeno de recuperación de empresas comenzó a expandirse debido a la vinculación entre la crisis socio-económica objetiva, por un lado, y la capacidad de transmisión de esta experiencia entre trabajadores, gracias a la coordinación de la acción colectiva por medio de movimientos sociales, por otro lado. Hacia 2005, se calculaba que existían cerca de 160 empresas recuperadas en todo el país, con alrededor de 9.000 trabajadores vinculados a las mismas (Ruggeri, 2005). Al momento de nuestro trabajo de campo el número había ascendido a cerca de 200 casos. Las ramas metalúrgicas y otras manufacturas, el sector gráfico, alimenticio, etc., constituyen los rubros más destacados del fenómeno. Los trabajadores que protagonizan estos casos provienen, en primer lugar, de fábricas y empresas pertenecientes a las fracciones más débiles de la pequeña y mediana burguesía, y constituyeron luchas claramente defensivas, en las cuales se trataba de salvar la continuidad laboral. Lo que alentó este tipo de acción colectiva de los trabajadores fue la ausencia de respuesta al conflicto laboral por parte de los empresarios, las instituciones de intermediación laboral y (en muchos casos) las organizaciones sindicales. Por tanto, el contexto social y político ofrecía incentivos para aferrarse a esta alternativa de mantenimiento de la fuente laboral, como último recurso visualizado por los trabajadores para no caer bajo la amenaza de la desafiliación social.

El impulso inicial a la acción colectiva fue de supervivencia frente a tal cuadro social ("Nosotros no empezamos esto porque quisimos hacer la revolución, fue la necesidad lo que nos llevo a tener esta lucha" -Socio de la cooperativa Unidos por el Calzado-). Además, en el momento en que comienzan a extenderse y hacerse visibles las recuperaciones de empresas, y a constituirse en un movimiento social nutrido de organizaciones formales, el contexto político general estuvo marcado por el hecho de que se había reducido el margen político para continuar con una salida represiva de la crisis social, tal como fue característico de los años anteriores. Por 
tanto, en el imaginario colectivo estuvo presente que el peligro de la represión estatal, que constituye el principal elemento disuasivo de la movilización social (Tarrow, 1997; Tilly, 1978), consistía en una medida políticamente difícil de implementar por parte de las autoridades públicas, lo cual implica un aliciente para este tipo de acción colectiva porque no inhibe su expansión a otros casos. A modo de ilustración, un trabajador gráfico expresa un imaginario extendido:

"En la policía nadie se quería hacer cargo de posibles victimas si entraban a la fábrica a reprimirnos y desalojarnos, ya venían del quilombo del 2001, porque esto fue en abril de 2002. Estaba muy fresco aque1lo. Llaman al juez y le preguntan si se hacía responsable de muertes. El juez pensaba que había ocho personas adentro de la fábrica y eso le parecía imposible. Pero se entero de que había más de 200, por la solidaridad que tuvimos, y con la calle llena de gente. Entonces dio marcha atrás, ordenó que quedaran sólo unos pocos policías custodiando y se retiren el resto" (Socio de la cooperativa Chilavert).

Por el contrario, el Estado ha encauzado estos procesos favoreciendo la formación de cooperativas de trabajo, a la vez que rechazaba otras opciones, como la estatización de las empresas bajo el control obrero de la producción. De hecho, distintos representantes de casi todo el arco político han acompañado estos procesos como forma de recuperar capital político tras la crisis nacional de los años 2001 y 2002. En este sentido, el repertorio de acción colectiva basado en la recuperación de empresas no puede considerarse como el resultado de la acción estratégica de un solo actor colectivo, sino como cristalización de la interacción y/o disputa de distintas propuestas de acción por parte de un conjunto de actores (Tilly, 2002) con distintos recursos políticos y sociales.

Otro tipo de incentivos están impulsados por la dinámica del propio movimiento social, como la construcción de redes de asociaciones que facilitan la acción colectiva: la existencia de un know-how consolidado, promovido y difundido por organizaciones del movimiento de empresas recuperadas. En algunos casos, tales vínculos se originan en que delegados internos o referentes de los trabajadores de la empresa en crisis tienen contactos gremiales, directos o indirectos, con dirigentes del movimiento social. En otras ocasiones, simplemente algunos trabajadores de las empresas en crisis tienen vínculos personales con trabajadores de alguna empresa recuperada, y que en muchos casos han resultado fundamentales para transmitir la opción de la recuperación.

\section{Incentivos de la movilización}

Para dar un paso más en la comprensión sociológica de la movilización, construimos una tipología de incentivos que ayudan a interpretar las distintas formas de participar dentro del movimiento social. En primer lugar, un grupo de trabajadores 
que conducen políticamente a sus empresas participan activamente en el movimiento con la expectativa de acumular poder político, incluyendo distintas posiciones ideológicas de izquierda, socialcristianas y peronistas, y/o por la creencia militante de cambio social que puede conllevar la extensión de estas experiencias. Implica la idea de que es necesario fortalecer a las empresas recuperadas como condición de existencia de un espacio socio-político nuevo, autónomo, y con capacidad de dar respuestas positivas a las luchas sociales y laborales que no encuentran canalización en los espacios tradicionales. Tomamos como ilustración el relato de un trabajador gráfico:

"La formación del movimiento fue una cosa bastante a pulmón, pura militancia viste. No se, hay tal ocupación en tal taller, y se salía, se hacia un piquete. Después había que irse a una reunión del movimiento... Era todo a pulmón, pero había energía, ojo. Los referentes de base, vamos a decir, creían en esto, i,entendés? Entonces se movían, estaban acá, allá, iban a los sindicatos, iban a la Legislatura, iban a una biblioteca, iban a una universidad, todo era movimiento, se llamaba a concentraciones, charlas, o sea, en ese momento había mucha energía porque la propuesta de cambio era diferente" (Socio de la Cooperativa Patricios).

Un segundo tipo de orientación consiste en participar del movimiento con criterios pragmáticos, buscando ventajas corporativas, sin interés político o ideológico definido. En esta orientación no prevalece la voluntad de poder, ni interesan tanto los proyectos, orientaciones y/o tradiciones políticas, porque la relación con la política es puramente instrumental. Lo importante es fortalecer económicamente a la cooperativa y garantizar la seguridad laboral. El siguiente fragmento ilustra esta variante:

"Nosotros participamos del movimiento para afianzar nuestro laburo, no nos interesa si los demás son radicales o peronistas, esas cosas tienen que quedar al margen (...) Pero esto de participar en espacios políticos no es pérdida de tiempo, porque lamentablemente nosotros estamos acá adentro por la política. La realidad es esa. Porque ellos nos dieron la posibilidad de estar acá adentro, porque votaron las leyes y demás. Yo, por ejemplo, pienso que no le podés fallar a esa gente. Aunque hagan política con nosotros. Pero eso a mi no me importa, porque a mi me interesa que me den el laburo. Y yo a su vez, también hago mi juego con ellos, porque si yo puedo sacarles algo se lo saco. Me refiero a la gente de la política. Por eso no hay que alejarse de la gente del municipio, ni de los políticos, ni de las reuniones. Porque es bueno que te vean. Vos no sabes cuándo te van a precisar ni cuando vos los vas a precisar" (Socio de la Cooperativa San Justo). 
La tercera orientación la encarnan trabajadores que basan los motivos de su participación en las organizaciones del movimiento social según criterios de lealtad hacia algunos dirigentes y espacios políticos, debido a la ayuda recibida de parte de los mismos, tal como se ejemplifica en el siguiente relato:

"Nosotras participábamos porque de ellos (de una organización política del movimiento) recibimos ayuda en momentos difíciles, y veíamos que era importante que este espacio creciera" (Socia de la Cooperativa Cefomar).

Además de las orientaciones típicas de los trabajadores hacia la actividad política, existe otro eje que hace referencia al ámbito de direccionamiento, inversión y movilización de los recursos (materiales, organizativos, intelectuales, sociales) propios de cada empresa recuperada. Por una parte, una orientación "hacia afuera" de la propia empresa implica canalizar e invertir los recursos con los que cuentan los trabajadores no sólo hacia la producción en su cooperativa, sino también hacia la construcción de espacios colectivos que trasciendan el ámbito interno de su propia unidad productiva. Supone, por tanto, la existencia de incentivos para constituir organizaciones que articulen a las empresas recuperadas entre sí, junto con otros actores sociales con los que perciban ciertas afinidades socio-políticas. Se puede acoplar con el otro eje de análisis considerado: orientaciones politizadas y pragmáticas, ya que ambas son articulables con la orientación "hacia afuera" y permiten comprender distintos sentidos típicos de la acción colectiva de los trabajadores. Por otra parte, una orientación "hacia adentro" de la propia organización implica direccionar sus recursos hacia el fortalecimiento de la empresa/cooperativa, siendo que los esfuerzos de construcción colectiva o política no forman parte de sus incentivos. Por tanto, es una orientación no articulable con un tipo de orientación politizada que, por definición, implica trascender el ámbito interno de la propia organización.

La orientación politizada no predomina entre los trabajadores de base, aunque un sector de ellos vivió el proceso de movilización asumiendo posiciones politizadas, respondiendo a distintas tendencias ideológicas que mencionamos. Pero en la mayoría, y a tono con la situación general de la clase trabajadora argentina en las últimas décadas (Godio, 2000), parece prevalecer la voluntad de continuar trabajando dignamente, pero sobre la base de un descreimiento respecto de lo positivo que pudiera ser involucrarse en la militancia social y política, lo cual impacta negativamente en la participación activa. La orientación politizada, por tanto, está presente en las conducciones de las empresas que tienen trayectoria de militancia social o sindical, a la vez que la orientación pragmática es más afín con las conducciones sin aquél bagaje. La orientación "hacia adentro" de la empresa también responde a conducciones apolíticas, que sostienen un proyecto más "empresarial" y poco participativo, aunque representa a una minoría de casos. 


\section{Estructuras de movilización y articulación económica}

La Economía Social da cuenta de aquella parte de la economía integrada por organizaciones privadas que comparten entre sí cuatro características: a) finalidad de servicio a sus miembros o a la colectividad antes que finalidad de lucro; b) autonomía de gestión; c) procesos democráticos de toma de decisiones; d) primacía de las personas y del trabajo sobre el capital en el reparto de las rentas (Morales et al. 2004; Monzón, 1989). Tales organizaciones, sin embargo, no se pueden considerar individualmente debido a que el concepto de Economía Social hace referencia a la interrelación productiva entre empresas sociales, en tanto que

"la esencialidad social de una empresa aisladamente considerada no depende, en última instancia, de que en ella se recreen de forma microscópica relaciones de poder no capitalistas. La firmeza de los principios a nivel celular carece de sentido si no se toma en cuenta al mismo tiempo el marco institucional, las relaciones clave entre los grandes agregados" (Monzón y Defourny, s/f: 2).

Dentro de la economía autogestionaria, las cooperativas constituyen la variante organizativa más extendida (Morales et al. 2004), y su control por los trabajadores tiene tres características: la participación en la toma de decisiones, el reparto de los beneficios y la propiedad en manos de los trabajadores, todo lo cual influye en sus estrategias económicas. Dicho esto, sostenemos que la Economía Social en tanto interrelación estructurada entre estos tipos de empresas supone la acción colectiva y la movilización, y trasciende la perspectiva económica. Para ello analizamos las condiciones sociales que permiten la articulación colectiva y la construcción de espacios de economía social, centrando la atención en la movilización de un conjunto diverso de recursos por parte del movimiento social de empresas recuperadas.

Inicialmente la acción colectiva y la movilización de los trabajadores estuvieron conducidas y dinamizadas por los sectores "politizados", según nuestra categorización anterior. Bajo sus impulsos se conformaron distintas organizaciones con posturas políticas, tradiciones ideológicas y organizativas diferentes, y que trataron de coordinar y conducir la recuperación de empresas, asesorando en las tácticas y estrategias a seguir en cada caso, negociando con funcionarios de organismos estatales y/o de juzgados, con legisladores, y demás organizaciones sociales. Al respecto, desde el propio inicio de este movimiento existieron diferentes criterios organizativos y alternativas políticas en juego, que estuvieron condicionadas, a su vez, por las propias propuestas estatales de encauzamiento del conflicto. Así, en primer lugar, se ubica la opción de conformar una federación de cooperativas (Federación de Cooperativas de Trabajo de Empresas Recuperadas -FENCOOTER-), vinculada orgánicamente al Estado mediante el Instituto Nacional de Economía Social (INAES).

En segundo lugar, existió la alternativa de la estatización de las empresas junto con el control obrero de la producción, que implicaba rechazar la figura cooperativa, 
que estuvo conducida por fuerzas políticas y sindicales de izquierda (Petras y Veltmeyer, 2002). La ausencia de condiciones políticas determinó que esta variante no prosperara y, al cabo de pocos años el espacio político que articulaba esta solución terminó agotándose. En tercer lugar, se halla la conformación de movimientos sociales autónomos de los partidos políticos, que apoyan pragmáticamente la adopción de la figura legal de cooperativa de trabajo, aunque originalmente no se identifican como federación de cooperativas, sino como un movimiento de trabajadores con pretensiones de incorporar otras experiencias organizativas de los denominados sectores populares. De esta forma se constituyó el Movimiento Nacional de Empresas Recuperadas (MNER), que incluyó a un grupo mayoritario de casos. Allí abrevaron diferentes tradiciones políticas, ideológicas y sociales, inscriptas en la tradición nacional-popular argentina (Godio, 2000), relacionadas con sectores sindicales (como metalúrgicos y gráficos) y políticos de la izquierda peronista, socialcristianos y de centro-izquierda, así como de la militancia social y grupos universitarios que apoyaron al movimiento. En una línea similar se conformó el Movimiento Nacional de Fábricas Recuperadas por sus Trabajadores (MNFRT) a comienzos de 2003, que pasará a constituir un espacio, hasta la actualidad, que brinda cierta cobertura político-corporativa a sus integrantes, y le permite a su conducción constituirse en interlocutor válido de este sector, frente a distintas estrategias de negociación con el Estado y otros actores sociales.

E1 MNER era la organización mayoritaria hacia el 2004-2005 (Ruggeri, 2005; Rebón, 2004). A partir de esta época experimentó un proceso de descomposición política que concluyó con su virtual agotamiento desde los inicios de 2006. Unos años se había desarticulado el FEENCOTER así como el espacio conducido por la izquierda a favor de la estatización con control obrero de la producción. De las primeras organizaciones del movimiento, por tanto, se mantiene hasta la actualidad el MNFRT. Los motivos de las crisis políticas y desmoronamientos organizativos del movimiento hacia mediados de la década del 2000 remiten a una incapacidad política general de conformar un espacio unificado, asumiendo y procesando internamente las diferencias y heterogeneidades de un movimiento complejo, pero con intereses objetivos comunes. Sin embargo, tras estos primeros fracasos políticoorganizativos, se están erigiendo nuevas organizaciones con voluntad de conducir el movimiento. Respecto de las disposiciones a la acción colectiva observadas luego de las rupturas internas, que muchos visualizaron como fracasos organizativos y que reflejan las dificultas políticas de construcción colectiva, hallamos tres tipos dominantes. En primer lugar, existen empresas recuperadas que están orientadas hacia posiciones individuales, aisladas del resto, como resultado de la decepción de su experiencia colectiva en el movimiento. Esta postura es consecuente con una orientación previa de sus integrantes (o conducciones) basada en la lealtad a ciertas organizaciones o dirigentes, o bien en la confianza inicial en las potencialidades de ciertos espacios organizativos que luego no se tradujeron a la realidad. En segundo lugar, se observan conducciones de empresas recuperadas que, frente a la desilusión político-organizativa anterior, buscan alternativas diferentes. Esta posición, por su 
parte, es coherente con la orientación militante respecto de la participación en la acción colectiva. Una tercera orientación, que constituiría un punto intermedio, está constituida aquellas empresas que, tras la decepción por las divisiones dentro movimiento, se encuadran en algún espacio con el único objetivo de pertenecer a una organización y disponer de cierta cobertura política o corporativa, lo cual es coherente con orientaciones basadas en el pragmatismo.

La novedad de las nuevas organizaciones que se conformaron en los últimos años es que prevalece el criterio, inicialmente pragmático, de asumir formatos provenientes del movimiento cooperativo. Concretamente, varios agrupamientos (no todos) adoptan la figura de federaciones o cooperativas de segundo grado (que en los inicios del MNER fue rechazada como opción estratégica porque excluía organizaciones sociales de otras características organizativas), y ello debido a que se adapta mejor a la articulación institucional entre empresas recuperadas que tienen la forma de cooperativas de trabajo. En esta línea se inscribe la Federación Argentina de Cooperativas de Trabajadores Autogestionados (FACTA), integrada por un amplio conglomerado de empresas recuperadas y cooperativas de trabajo propiamente dichas. También se encuentra la Federación de Empresas Recuperadas y Cooperativas de Trabajo (FERyCOOTRA). Dicha federación se conformó bajo la impronta política de un sindicato metalúrgico, la Unión Obrera Metalúrgica de Quilmes, que conduce a un grupo importante de empresas recuperadas. Otro espacio que se ha conformado es La Federación de Cooperativas de Trabajo Red Gráfica Cooperativa Limitada, constituida por empresas recuperadas del sector gráfico, y políticamente integrada con la Federación de Cooperativas de Trabajo (FECOOTRA) y con el sindicato gráfico Federación Gráfica Bonaerense (FGB).

Sin embargo, otros espacios políticos no asumen la forma de federación de cooperativas, como la Asociación Nacional de Trabajadores Autogestionados (ANTACTA), que se conformó a fines de 2005, y está integrada por cerca de 80 organizaciones autogestionarias. Esta organización intenta constituirse en un sindicato de trabajadores autogestionados, promovido por la Central de Trabajadores Argentinos (CTA). Por lo demás, se observa que también se articulan organizaciones puntuales, impulsadas por la proximidad territorial entre empresas recuperadas, con una orientación predominantemente pragmática, que consiste en reunirlas para negociar con más poder temas puntuales que corresponden a la órbita de los poderes municipales a los que pertenecen. Así, se formó el Foro de Fábricas Recuperadas del municipio de La Matanza (Provincia de Buenos Aires). Hasta el momento del trabajo de campo, estas corrientes no han logrado una síntesis política nueva, por lo cual trabajan de manera separada. La posibilidad de un acuerdo político requiere de un trabajo de construcción de confianza entre las partes, en base a necesidades comunes objetivas, que por el momento ha cristalizado débilmente en la Unión de Federaciones de Cooperativas de Trabajo, que agrupa a las federaciones mencionadas junto a otras tradicionales y aquellas cooperativas nacidas de los planes estatales de construcción de viviendas populares (Acosta y Raspall Galli, 2008), constituyendo un avance institucional aunque con poca sustancialidad política. En definitiva, muchos referentes de conducciones politizadas, que son quienes dinamizan el 
movimiento social, ven en la organización de cooperativas de segundo grado un formato adecuado a las necesidades de crecimiento político y económico de las empresas recuperadas, y que puede facilitar una mayor acumulación política, un mayor reconocimiento por parte del Estado y de otros sectores sociales, y que tal construcción debería redundar en más posibilidades de articulación económica y productiva entre cooperativas. La evolución organizativa temporal del movimiento social, por tanto, refleja que sus repertorios de construcción política están estrechamente relacionados, y a veces en conflicto, con las propuestas de encauzamiento estatales, y expresan dicha dialéctica.

La evidencia empírica indica que la autogestión de las empresas recuperadas en el mercado está sujeta a esta evolución organizacional del movimiento social. Hasta el momento, han prevalecido estrategias individuales y adaptativas de inserción económica, que se corresponden con una etapa de formación de las primeras organizaciones políticas del movimiento, marcada por luchas de reconocimiento jurídico, de construcción política y de ausencia de proyectos de integración productiva.

"Nosotros, como movimiento, creo que fuimos eficaces en ayudar a los compañeros a recuperar sus empresas, a resistir las presiones legales que tuvimos, o sea, en los temas urgentes, pero nos faltó un proyecto productivo, hacíamos lo podíamos por nuestra cuenta. Ahora estamos en otra etapa, donde tenemos que avanzar también en un proyecto económico común" (socio de la cooperativa BAUEN).

En este sentido, se observa una evolución, práctica y discursiva, de un sector importante de empresas recuperadas desde posiciones que concebían al cooperativismo como una solución pragmática, adecuada al contexto de oportunidades presentado, hacia una concepción de naturaleza estratégica vinculada con las potencialidades de la economía social.

En términos económicos, las empresas recuperadas no constituyen organizaciones capitalistas que maximizan la rentabilidad por sobre el resto de las variables; por el contrario, se observa que se mantienen los puestos de trabajo sacrificando rentabilidad o volumen de producción en períodos de inestabilidad. En cierto sentido, prevalece la cultura del trabajo por sobre la lógica empresarial capitalista. Sin embargo, resulta necesario que la empresa recuperada sea sustentable en el mercado, aunque el criterio básico de viabilidad no sea maximizar los excedentes, sino sostener una actividad productiva que permita un retiro mensual para los trabajadores. Inicialmente, la gran mayoría de las empresas recuperadas adoptaron estrategias precarias, fundamentalmente el trabajo por encargo complementado con la liquidación de stocks para formar un mínimo capital de trabajo. Un sector de las mismas ha logrado recuperar viejos clientes y proveedores, conquistar otros del rubro, y fortalecer su posición en el mercado. Otro grupo ha encontrado mayores dificultades de consolidarse y ha debido, forzosamente, reconvertirse a otras actividades. Sin embargo, en los últimos años han comenzado a implementarse experiencias (algunas más avanzadas y otras más embrionarias) de integración económica entre 
las empresas recuperadas. Este tipo de estrategia colectiva consiste en la formación de redes entre empresas recuperadas con el objetivo de compartir recursos, mercados, condiciones de negociación con proveedores, etc., que complementan las opciones individuales originales de cada unidad productiva. Constituyen avances en el grado de interrelación y articulación económica y, por tanto, en el grado de movilización, entendido como el proceso por el cual el grupo adquiere el control colectivo sobre los recursos que necesita para su acción colectiva.

Concretamente, se ha impulsado una red de complementación productiva entre empresas gráficas (la Red Gráfica), con el apoyo del sindicato gráfico, que asume la acción colectiva de articular una política común de compras de insumos para obtener mejores precios y condiciones financieras con el fin de reducir costos de producción y afrontar más eficientemente las limitaciones típicas de pymes aisladas de baja capacidad productiva:

"La red grafica es una herramienta que se crea a partir de que se ve la necesidad, por ejemplo, de que si va la empresa Chilavert sola a comprar papel se lo van a dar a un precio, porque va a comprar 10 toneladas. Ahora si va la Red, que compra 300 toneladas, va a ser otro precio. Y eso es con el papel, con la tinta, con todo" (Socio de la cooperativa Patricios).

En cuanto a su coordinación interna, la Red Gráfica centraliza los pedidos que los clientes realizan y analiza las posibilidades de complementación entre empresas para responder al pedido. Si no es posible la complementación, deriva esta demanda a cada cooperativa integrante para que elaboren un presupuesto y un plazo de entrega, y luego elige a quién asigna el trabajo en función de la mejor oferta presentada.

Otro caso de articulación productiva lo constituye la red de empresas metalúrgicas (aunque también participan químicas, plásticas) de la zona sur de la provincia de Buenos Aires. En este consorcio productivo también ha resultado decisiva la articulación política previa entre las empresas recuperadas, el sindicato de la Unión Obrera Metalúrgica de Quilmes y sectores universitarios, que aportaron una serie de vínculos internacionales estratégicos que facilitaron financiamiento y asesoramiento productivo. Esta red forma una estructura logística que permite una vinculación online entre los ordenadores de las doce empresas recuperadas que forman el espacio. Dicha interconexión facilita el conocimiento sobre la capacidad productiva de cada una de las empresas a cada momento. Esta posibilidad es evaluada como un gran avance para la coordinación colectiva de la actividad productiva:

"Ahora estamos interconectados, y gracias a eso se sabe la cantidad de hora-ocio, por ejemplo, que cada uno tiene en tornería. Así los otros saben que pueden poner algo para hacer en tornería en una de esas 12 recuperadas. Si tienen hora-ocio en pintura, todos saben que pueden hacer un trabajo de pintura en una empresa recuperada por parte de otra recuperada. O sea, están las bases tecnológicas para que funcionen en red" (Dirigente de la UOM de Quilmes, responsable de relaciones con las empresas recuperadas). 
También han elaborado un Centro de Diseño, que posibilita nuevos procesos de fabricación, capacitación y asesoramiento externo. Sin embargo, como en el caso de la Red Gráfica, son experiencias que están en etapas de experimentación de formas de complementación productiva.

El discurso de la integración productiva y la economía social se va constituyendo, de este modo, en un marco interpretativo presente entre las conducciones de las empresas recuperadas. Los ejemplos señalados inspiran estrategias similares en empresas recuperadas que están en una etapa menos avanzada de articulación económica, y que permite la circulación de propuestas de elaboración de proyectos similares, por ejemplo, entre hoteles recuperados ubicados a lo largo del país:

"El cooperativismo aporta un proyecto de producción. Este es un desafío fundamental. Como no hay un camino marcado, las soluciones las vamos tanteando. Nos parece muy bueno lo que hace la Red Gráfica. Acá existen hoteles, que son empresas recuperadas, en Mar del Plata, Mendoza, Buenos Aires, etc. y se podría hacer un plan de complementación entre nosotros. O sea, además de comprar insumos comunes, como sábanas, utensilios, material de limpieza, etc., se pueden armar paquetes turísticos ofreciendo estadías en diferentes zonas turísticas del país, porque hay hoteles ubicados en ciudades que ofrecen muchas alternativas turísticas" (Socio de la cooperativa BAUEN).

De esta manera, parece ir complejizándose el repertorio económico de la recuperación de empresas debido a la transferibilidad de estas formas de acción colectiva, que permite a los actores movilizarse sin la carga del aprendizaje o la invención de técnicas novedosas para los protagonistas.

\section{Conclusión}

El análisis efectuado nos remite a la cuestión general según la cual, en las condiciones históricas actuales, debemos estudiar las relaciones laborales y los desafíos del movimiento obrero dentro del esquema de los movimientos sociales. En este sentido, el poder de los movimientos obreros excede lo que la tasa de densidad sindical sugiere, ya que la fuente de poder más importante de los trabajadores es su propio dinamismo sociopolítico. Concretamente, en nuestro caso hemos considerado la dimensión cualitativa de las primeras estrategias de coordinación económica por parte de las empresas recuperadas, que implica analizar el tipo de vínculo social que ellas establecen, sus orientaciones estratégicas, y sus soportes sociales. En términos sociológicos, resulta relevante la articulación política previa que antecede a los acuerdos económicos porque es la instancia que permite discutir y elaborar consensos sobre los proyectos productivos, a la vez que favorece la circulación de conocimientos y experiencias 
acumuladas dentro del movimiento general. La consolidación de varios agrupamientos políticos de empresas autogestionadas, con conducciones internas estables, si bien expresa divisiones dentro del movimiento social, permite actuar dentro de espacios comunes a distintos grupos de empresas recuperadas y proyectar desde allí estrategias autónomas de fortalecimiento económico.

Por todo ello, debemos señalar que la lógica social que facilita una articulación productiva entre empresas recuperadas requiere, además de requisitos tecnoproductivos, de una articulación política previa entre los actores sociales. Las opciones de configurar redes económicas surgen como posibles y viables en la medida en que sus integrantes, especialmente sus conducciones políticas, hayan acordado el sentido, la orientación y los intereses materiales y políticos que se ponen en juego en este tipo de emprendimientos colectivos. Por el contrario, si prevalece la incapacidad de acordar políticamente entre las conducciones de empresas recuperadas para avanzar en el proceso de articulación y/o unificación de las organizaciones, se ausentan los soportes políticos de las estrategias colectivas y, por tanto, disminuyen las posibilidades de ganar niveles de autonomía económica y productiva. Por ello, la acción colectiva del movimiento social explica las tendencias incipientes de conformación de espacios económicos comunes entre empresas recuperadas, apostando por el pasaje de la condición de empresas sociales al de la construcción de una economía social, en tanto ámbito de gestión, producción y comercialización inter-organizativa. En este sentido, las opciones económicas que adoptan las empresas recuperadas no se pueden analizar sin considerar previamente la movilización político-organizacional.

\section{Referencias bibliográficas}

Acosta, M. y Raspall Galli, T. (2008). La articulación de las cooperativas de vivienda con el Estado y otros actores sociales, en http://www.econ.uba.ar/cesot/docs/documento\%2061.pdf

Beccaria, L. (2007). Pobreza, en Población y bienestar en la Argentina del primero al segundo centenario, Tomo II, Torrado, S. (Coord.). Edhasa. Buenos Aires.

Beccaria, L. (2001). Empleo e integración social. Fondo de Cultura Económica. Buenos Aires.

Biyanwila, J. (2008). Re-empowering labour: knowledge, ontology and counterhegemony, en The annual conference of The Australian Sociological Association 2008, Re-imagining sociology, 2-5 de Diciembre, Melbourne.

Bronfenbrenner, K.; Juravich, T. (1998). It takes more than housecalls: organizing to win with a comprehensive union-building strategy, en Organizing to win: new research on union strategies, Bronfenbrenner et al. (Coords.). Cornell University Press. Ithaca, Nueva York. 
Casquette, J. (1998). Política, cultura y movimientos sociales. Bakeaz. Bilbao.

Castel, R. (2000). Encuadre de la exclusión, en La exclusión: bordeando sus fronteras. Definiciones y matices, Karsz, S. (Coord.). Gedisa. España.

Charlwood, A. (2002). Why do Non-Union employees want to Unionize? Evidence form Great Britain. British Journal of Industrial Relations, Vol. 40, Num. 3.

Godio, J. (2000). Historia del movimiento obrero argentino (1870-2000). El Corregidor. Buenos Aires.

Heery, E.; Simms, M.; Delbridge, R.; Salmon, J. y Simpson, D. (2003). Trade union recruitment policy in Britain: form and effects, en Union organizing: campaigning for union recognition, Gall, G. (Coord.). Routledge. Londres.

Hobsbawm, E. (1989). Politics for a rational left. Verso. Londres.

Hyman, R. (1971). Marxism and sociology of trade unionism. Pluto Press. Londres.

Hyman, R. (1994). Changin trade unions identities and strategies, en New frontiers in European Industrial Relations, Hyman R. y Ferner, A. (Coords.). Blackwell. Oxford.

Hyman, R. (2001). Understanding european trade unionism: betwen market, class and society. Sage. Londres.

Ibarra, P.; Gomà, R.; González, R.; Martí, S. (2002). Los Nuevos Movimientos Sociales. El estado de la cuestión, en Creadores de democracia radical, Ibarra, P.; Martí, S. y Gomà, R. (Coords.). Icaria. Barcelona.

Jódar, P.; Ortíz, L.; Martí, J.; Martín, A. y Alós, R. (2005). Los perfiles de la afiliación sindical. Una propuesta metodológica a partir de un estudio de $\mathrm{CCOO}$ en Cataluña. Cuaderno de Relaciones Laborales, Vol. 22, Num. 2.

Kriesi, H. (1996). La estructura organizacional de los nuevos movimientos sociales en su contexto político, en Movimientos Sociales: perspectivas comparadas, McAdam, D., McCarthy, J., y Zald, M. (Comps.). Istmo. Madrid.

Lacalle, D. (2006). La clase obrera en España. Continuidades, transformaciones y cambios. El Viejo Topo. Barcelona.

Lambert, R. (2002): Labour movement renewal in the era of globalisation: Union responses in the South, en Theory and strategy of organised labour in the global political economy, Harrod, J. y O’Brien, R. (Coords.). Routledge. Londres.

Laraña, E. (1999). La construcción de los movimientos sociales. Alianza. Madrid. 
Laraña, E.; Gusfield, J. (1994). Los nuevos movimientos sociales. CIS. Madrid.

Mcadam, D. (1988): Political process and the development of black insurgency, 1930-1970. University of Chicago Press. Chicago.

Mcadam, D. (1994). Cultura y movimientos sociales, en Los nuevos movimientos sociales. Laraña, E. y Gusfield, J. (Comps.). CIS. Madrid.

Mcadam, D.; Mccarthy, J.; Zald, M. (1999). Oportunidades, estructuras de movilización y procesos enmarcadores: hacia una perspectiva sintética y comparada de los movimientos sociales, en Movimientos Sociales: perspectivas comparadas, McAdam, D., McCarthy, J., y Zald, M. (Comps.). Istmo. Madrid.

Melucci, A. (1994). “¿Qué hay de nuevo en los nuevos movimientos sociales?”, en Los nuevos movimientos sociales, Laraña, E. y Gusfield, J. (Comps.). CIS. Madrid.

Monzón, J. (1989). Las cooperativas de trabajo asociado en la literatura económica y en los hechos. MTSS. Madrid.

Monzón, J. ; Defourny, J. (s/f): La economía social, entre economía capitalista y economía pública, Universidad de Chile, Curso de Formación General, en http://www.google.es/search?hl=es\&q=Monz $\% \mathrm{C} 3 \% \mathrm{~B} 3 \mathrm{n}+\mathrm{y}+$ Defourny+\%2B+\%E2 $\% 80 \% 9 \mathrm{Cla}+$ econom $\% \mathrm{C} 3 \% \mathrm{ADa}+$ social $\% 2 \mathrm{C}+$ entre+econom $\% \mathrm{C} 3 \% \mathrm{ADa}+$ capitalista $+\mathrm{y}+\mathrm{econom} \% \mathrm{C3} \% \mathrm{ADa}+\mathrm{p} \% \mathrm{C} 3 \% \mathrm{BAblica} \% \mathrm{E} 2 \% 80 \% 9 \mathrm{D} \& \mathrm{btnG}=$ Buscar\&meta $=$

Moody, K. (1997). Trade unions across borders, en New Left Review, 25

Morales, A., Monzón, J.; Chávez, R. (2004). La empresa autogestionada en retrospectiva, en Análisis económico de la empresa autogestionada, Morales, A., Monzón, J., Chávez, R. CIRIEC. España.

Mouriaux, R.; Beroud, S. (2000). Para una definición del concepto de movimiento social. OSAL, Núm. 1, CLACSO. Buenos Aires.

Petras, J.; Veltmeyer, H. (2002). Auto-gestión de trabajadores en una perspectiva histórica, en Produciendo Realidad. Las Empresas Comunitarias, Carpintero, E. y Hernandez, M. (Comps.). Topia- La Maza. Buenos Aires.

Rapoport, M. (2005). Historia económica, política y social de la Argentina (18802003). Editorial Emecé. Buenos Aires.

Rebón, J. (2004). Desobedeciendo al desempleo. La experiencia de las empresas recuperadas. Ediciones Picaso/La Rosa Blindada. Buenos Aires.

Robles, J. (2002). El reto de la participación. Movimientos Sociales y Organización. Antonio Machado Libros. Madrid. 
Ruggeri, A. (2005). Las empresas recuperadas en Argentina, Facultad de Filosofía y Letras, UBA. Buenos Aires.

Salvia, A. (2004). Segregación y nueva marginalidad en tiempos de cambio social enArgentina.

http://www.catedras.fsoc.uba.ar/salvia/programa/biblioteca/bolsa/p17_05.doc

Senén González, C.; Haidar, J. (2009). Los debates acerca de la 'revitalización sindical' y su aplicación en el análisis sectorial en Argentina. Revista Latinoamericana de Estudios del Trabajo, $2^{\circ}$. Epoca, Vol. 22, Num.2.

Snow, D.; Zurcher, L.; Ekland-Olson, S. (1980). Social networks and social movements: a microestructural approach to differential recruitment. American Sociological Review, Núm. 2.

Sullivan, R. (2010): Why the labor movement is not a movement. New Labor Forum, Vol 19, Num. 2.

Sullivan, R. (2004). Mapping the dimensions of labor revitalization: movement innovators survey the California frontier. Sociological Focus, Vol. 37, Num.3.

Tarrow, S. (2002). Ciclos de acción colectiva: entre los momentos de locura y el repertorio de contestación, en Protesta social. Repertorios y ciclos de acción colectiva, Traugott, M. (Comp.). Hacer Editorial. Barcelona.

Tarrow, S. (1997). El poder en movimiento. Los movimientos sociales, la acción colectiva y la política. Alianza Editorial. Madrid.

Tilly, Ch. (2002). Repertorios de acción contestataria en Gran Bretaña, en Protesta social. Repertorios y ciclos de acción colectiva, Traugott, M. (Comp.). Hacer Editorial. Barcelona

Tilly, Ch. (1978). From mobilization to revolution. Addison-Wesley Publishing Company. EEUU.

Touraine, A. (1990). La sociedad post-industrial. Ariel. Barcelona.

Waterman, P. (2005). Labour and new social movements in a globalising World system: the future of the past. Labour History, Vol.46; Num. 2.

Webster, E.; Lambert, R.; Bezuidenhout, A. (2008). Grounding globalization: labour in the age of insecurity. Blackwell. Londres.

Wright, E. (1994). Reflexionando, una vez más, sobre el concepto de estructura de clases, en Carabaña, J. y De Francisco, A. (Comps.).Teorías contemporáneas de las clases sociales, Editorial Pablo Iglesias. Madrid.

Zald, M. (1999). Cultura, ideología y creación de marcos estratégicos, en Movimientos Sociales: perspectivas comparadas, McAdam, D., McCarthy, J., y Zald, M. (Comps.). Istmo. Madrid. 